\title{
Elephant Rescue in Sri Lanka
}

\section{David M. Jones}

At Uda Walawe in Sri Lanka (Ceylon) a group of about thirty elephants have become isolated in a small pocket of jungle as a result of large-scale agricultural development. There is not sufficient food for them and they are completely surrounded by farms. Inevitably they raid the fields at night, and are shot at by the farmers; some are injured, have become dangerous and killed people. Forced to act, the Wildlife Department has been trying to move them. The author, who is resident Veterinary Officer at Whipsnade Park in England, assisted with the second removal, and here describes how it was done and some of the problems.

In southern Sri Lanka, the Uda Walawe river valley has been developed for agriculture, and most of the secondary scrub jungle has been cleared. Near the village of Angunukolapelessa, areas of dense thorn scrub, varying from 50 to 200 acres, still remain, and here a group of about thirty wild elephants Elephas maximus have become isolated. The herd, comprising adult cows, some with calves, together with juveniles and sub-adults of both sexes, frequently separates into two or three smaller groups, and is often accompanied by adult bulls, although some of these appear to remain solitary. The small areas of scrub do not provide them with sufficient food, and they forage on the surrounding farmland at night, causing considerable damage. The local farmers try to drive them away, often by shooting at them, with the result that the larger animals particularly have a variety of chronic injuries. Continuous harassment has made some of the elephants dangerous, and several people have been killed.

Early in 1974 the Department of Wildlife Conservation captured three large adult bulls, all thought to be particularly aggressive to man. One of these became dangerous and unhandleable after capture, broke the restraining ropes and had to be destroyed. The other two died within three weeks of being caught, almost certainly due to prolonged stress, chronic injuries and poor physical condition prior to capture.

\section{Materials and Methods}

In July 1974, at the invitation of the Wildlife Department, the author went to Sri Lanka to assist with a second capture operation. Six more elephants were caught, using similar methods, but concentrating on animals under 2.2 metres ( $7 \mathrm{ft}$ ) in height because of the problems of handling the larger animals. On the basis of previous experience (Jones and Manton 1972) it was decided to use a mixture of the narcotic Etorphine and the sedative Acepromazine (Immobilon-Reckitts). The weapons used were a Dist-Inject model 60 and a long range Palmer Cap-Chur rifle, both of which employ an explosive charge to propel the dart. The $5 \mathrm{mls}$-capacity darts were of the standard Palmer design utilising an $8.0 \mathrm{~cm}$ long, $5.8 \mathrm{~mm}$ wide cuffed needle.

The density of the thorn scrub made it necessary to approach to within 10-15 metres of the elephants to get a clear view of them and so prevent the dart being deflected by branches. This became too hazardous on foot, so two 
heavy Caterpillar D7 bulldozers were used to approach and manoeuvre the elephants into a position where the neck, shoulders or hindquarters of a selected animal were clearly visible. Each bulldozer carried a veterinary surgeon with a dart gun, a ranger with a rifle, and a team of four or five men with ropes and veterinary equipment. The uneven, sometimes rocky ground, dense thorn bush, irrigation channels and the dust thrown up from the vehicle tracks often made it difficult to follow the animals as they moved at a fast walking pace from one area of scrub to another. The dart usually had to be fired from the manoeuvring bulldozer at a moving animal. Five elephants were immobilised in this way and a juvenile was caught manually.

Immediately an animal collapsed, it was positioned on its side and the trunk extended to facilitate breathing; the dart was removed and the wound packed with penicillin, which was also given together with corticosteroids, by intramuscular injection; the animal was then quickly secured with ropes to one or both of the bulldozers. This operation usually took about 20 minutes. To hold the smaller 1.7-metre animals, one bulldozer and a team of men were used, but for the larger animals, both machines were employed with the elephant tied between them. The antidote Diprenorphine (Revivon-Reckitts), was given into an auricular vein and the animals stood up two to seven minutes after the injection, but remained in a state of sedation for four to six hours. This had the advantage that they could be walked out of the scrub without undue stress to a point suitable for securing them. They were tied to two trees by a neck rope and ropes on one hind and one foreleg. The foreleg rope was later removed from the smaller animals. At regular intervals, usually twice a day, the ropes were moved from one leg to the other to minimise tissue damage. Long-acting penicillin was also given by intramuscular injection on the third and fifth days after capture. Fresh food and water were available continuously, and the animals were regularly sprayed with cold water during the warmest hours of the day.

\section{Discussion}

Very little work has been published on the capture of wild Asiatic elephants using drug immobilisation techniques. Gray and Nettashinghe (1960) successfully used Etorphine alone to immobilise three animals for marking, but, as far as is known, the technique had not been used before to move adult elephants, either African (Loxodonta africana) or Asian. The Department of Wildlife Conservation was requested to capture and move the elephants in the Angunukolapelessa area because of the damage to crops and the danger to human life. Destruction of the animals is apparently unacceptable on religious grounds. The Department decided initially to catch those adults which were suspected of having attacked and possibly killed people. The three animals caught earlier in the year with Etorphine alone (Attapattu 1974) were all approaching 3 metres in height and weighed an estimated 3500 to 4500 kilograms. Their poor condition and the fact that they were chronically injured before capture may have explained their aggression towards humans and probably contributed to the deaths of two of them. It is unlikely that adults of this age, size, condition and disposition would be suitable for domestication or relocation even if it were physically possible to remove them from Uda Walawe.

All the elephants, in both the earlier and later series, were immobilised 

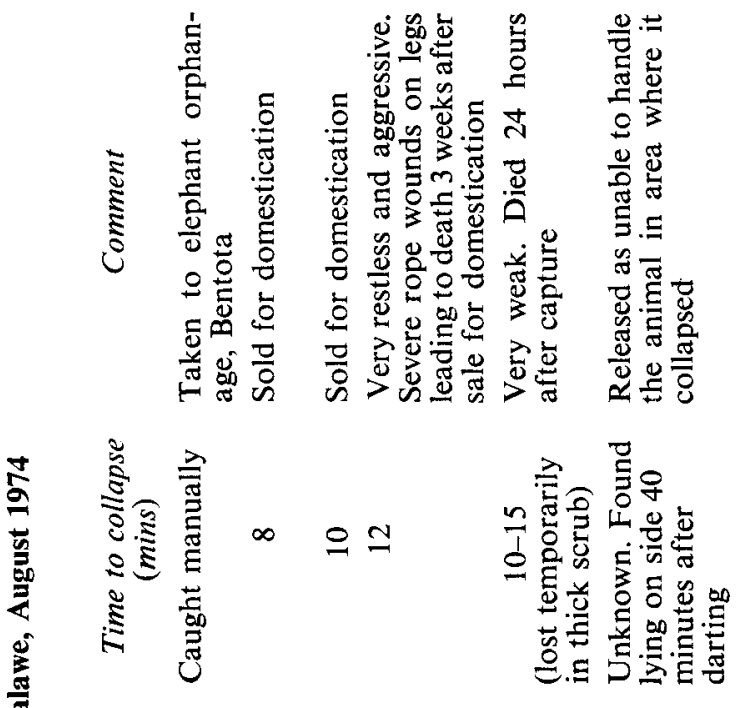

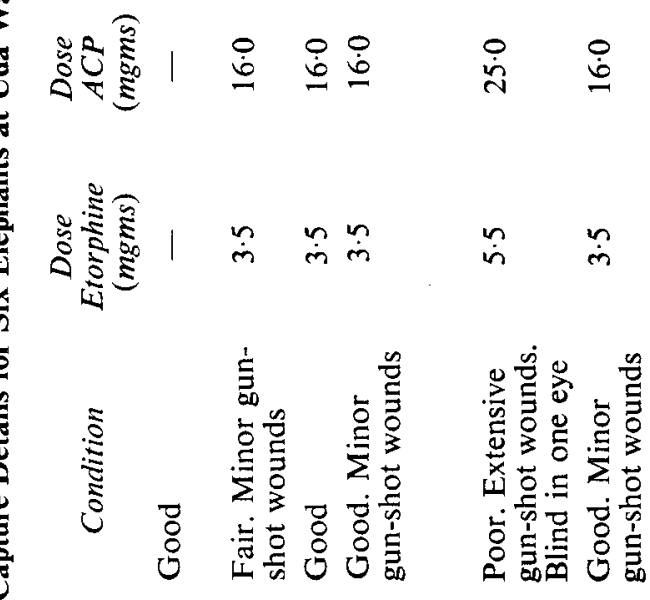

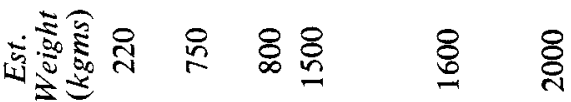

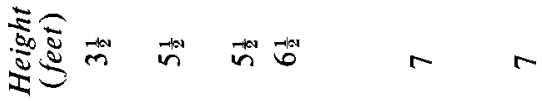

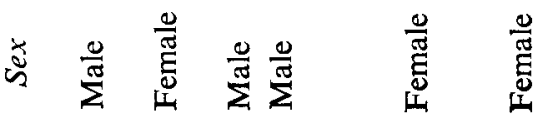


without any clinical problem; all recovered fully from the effects of the drugs and none of the deaths could be attributed to their use. The combination of Acepromazine with Etorphine reduces the dose rate of Etorphine needed to achieve immobilisation. In the previous operation $20 \mathrm{mgm}$ of Etorphine were used on one of the animals. Two darts, each containing $10 \mathrm{mgm}$ were necessary before deep narcosis was produced (Attapattu 1974). It is possible that the drug from the first dart was injected subcutaneously, as relatively short dart needles $(5 \mathrm{~cm}$.) were used. This would have delayed absorption of the drug and more would then have been needed to achieve the full effect. It is also possible that the drug had lost its potency with storage or that this was an individual variation affecting the one animal, a problem which occurs in many species from time to time.

With the Etorphine and Acepromazine combination, some residual sedation is noted after the state of deep narcosis has been reversed. It is important to move the animals at this time, as they are relatively tractable and the degree of stress is reduced. Although ropes have traditionally been used to hold newly caught elephants, there is a danger, however quiet the animal or experienced the handlers, that damage to the lower limbs will occur. It should be possible to replace this method by keeping newly caught elephants, certainly those under two tons, in strongly constructed steel and wood crates, a method that is now extensively used elsewhere for holding large mammals (Hirst, 1973; Hitchins, Keep and Rochat, 1972; Player, 1967). In this way the animal is restrained but not damaged, the stress of continual contact with crowds of onlookers is avoided, and it can be fed, watered and kept clean without undue physical risk to the handlers. Furthermore, such a method facilitates transport as the crate can be designed for haulage by a heavy tractor and be carried on a lorry.

Elephants over about 15 years of age or 2.2 metres in height are not as suitable as smaller individuals for domestication or reintroduction elsewhere. As the more severely injured and aggressive animals in Uda Walawe fall into this category, and as they have already proved difficult to handle and move in this area, consideration should be given to destroying them humanely. There are still nearly 30 animals in the group, as it is breeding well and more calves will probably be born. About 20 of the present group would be of 2 tons or less and could be moved in crates. The sale of some of these younger elephants, possibly the males, for domestication, would pay the costs of the operation.

\section{Conclusions and Summary}

(1) A combination of Etorphine and Acepromazine produced rapid and complete immobilisation in five young Asiatic elephants. There were no clinical problems associated with maintaining narcosis, and the residual sedation following reversal of the narcotic effect allowed the animals to be handled relatively easily and without undue stress for 4-6 hours after capture. (2) At Uda Walawe the only practical and safe way to approach these animals for darting was on a heavy bulldozer, which was also necessary for moving the animals after capture.

(3) The use of strong wood and steel crates instead of ropes for holding and moving elephants of up to two tons would reduce the stress and the risk of injury to newly caught animals.

(4) Owing to the difficulties of holding and relocating or domesticating the 
largest animals at Uda Walawe, and in view of their present temperament and condition, consideration should be given to destroying these animals humanely.

(5) The elephant group at Uda Walawe is breeding well. The Wildlife Department with its present facilities, cannot be expected to remove in one year many more than the annual increase in numbers. Destruction of the adults those over about two tons in weight and 2.2 metres in height would temporarily prevent a further population increase. The remaining elephants could be removed alive within one dry season, but to do this the Department would need to have on hand, all the time, two or three holding crates, a seven-ton lorry and two bulldozers. Outlets for the animals would have to be arranged prior to the operation so that none had to be held in the catching area for more than two days. This would make it possible to catch animals continuously once the operation had begun. The use of a light helicopter, despite the considerable practical difficulties in obtaining and operating it, could speed up the operation considerably and so might prove to be economically worthwhile. It could be used for finding the elephants, firing the dart, driving darted animals to a suitable point for handling, and co-ordinating the movements of bulldozers, crates and lorry.

\section{Acknowledgments}

The author would like to acknowledge the hospitality of the Department of Wildlife Conservation of Sri Lanka, in particular the Director at the time of the operation, Mr Saparamadu, and the Assistant Directors, Dr Meemaduma and Messrs de Alwis and Packeer. Dr Attapattu, the Department's Assistant Director of Research who carried out the first series of captures, gave much helpful advice. The General Brooke Memorial Fund gave equipment and drugs to the Department. Messrs Reckitt and Colman Ltd, gave the Etorphine and Diprenorphine.

\section{Drugs and Equipment}

Immobilon: $2.45 \mathrm{mgms}$ Etorphine Hydrochloride and 10.0 mgms Acepromazine Maleate per $1 \mathrm{ml}$. - Reckitt and Colman Ltd, Hull, England.

Revivon: 3.0 mgms Diprenorphine Hydrochloride per $1 \mathrm{ml}$. - Reckitt and Colman Ltd, Hull, England.

Dist-Inject Model 60 rifle: Syringe projector made by Peter Ott and Co., Oetlingerstrasse 81, CH-4007, Basle, Switzerland.

Long range Chap Chur rifle: Syringe projector made by Palmer Chemical \& Equipment Co. Inc, P.O. Box 867, Palmer Village, Douglasville, Georgia 30134, USA.

\section{References}

1. ATTAPATTU, S., 1974. Personal communication. Unpublished data.

2. GRAY, C. W. and NETTASHINGHE, A. P. W., 1970. A preliminary study on the Immobilisation of the Asiatic Elephant (Elephas maximus) utilising Etorphine (M.99). Zoologica 55 (3) p. 51.

3. HIRST, S. M., 1973. Transportation of Wild Animals, Chapter 12 in "The Capture and Care of Wild Animals", Ed. E. Young, Human and Rousseau, Cape Town.

4. HITCHINS, P. M., KEEP, M. E. and ROCHAT, K., 1972. The capture of Black Rhinoceros in Hluhluwe game reserve and their translocation to the Kruger National Park. Lammergeyer 17 p. 18.

5. JONES, D. M. and MANTON, V. J. A., 1972. Scientific Report of the Zoological Society of London (for Whipsnade Park) in $J$. Zool. Lond. 166, p. 541.

6. PLAYER, I. C., 1967. Translocation of White Rhinoceros in South Africa, Oryx 9, 2, p. 137. 